\title{
Mannosylated Polyrotaxanes for Increasing Cellular Uptake Efficiency in Macrophages through Receptor-Mediated Endocytosis
}

\author{
Kai Shibaguchi ${ }^{1}$, Atsushi Tamura ${ }^{2, * \mathbb{D}}$, Masahiko Terauchi ${ }^{2}$ (), Mitsuaki Matsumura ${ }^{1}$, \\ Hiroyuki Miura ${ }^{1}$ and Nobuhiko Yui ${ }^{2}$ \\ 1 Department of Restorative Sciences, Graduate School of Medical and Dental Sciences, \\ Tokyo Medical and Dental University (TMDU), 1-5-45 Yushima, Bunkyo, Tokyo 113-8549, Japan; \\ k.shibaguchi.fpro@tmd.ac.jp (K.S.); mmdent@mvd.biglobe.ne.jp (M.M.); h.miura.fpro@tmd.ac.jp (H.M.) \\ 2 Department of Organic Biomaterials, Institute of Biomaterials and Bioengineering, Tokyo Medical and \\ Dental University (TMDU), 2-3-10 Kanda-Surugadai, Chiyoda, Tokyo 101-0062, Japan; \\ terauchi.org@tmd.ac.jp (M.T.); yui.org@tmd.ac.jp (N.Y.) \\ * Correspondence: tamura.org@tmd.ac.jp; Tel.: +81-3-5280-8022
}

Academic Editor: Bernard Martel

Received: 27 December 2018; Accepted: 24 January 2019; Published: 26 January 2019

check for updates

\begin{abstract}
Macrophages play an important role in the regulation of inflammation and immune response as well as the pathogenesis of chronic inflammatory diseases and cancer. Therefore, targeted delivery of therapeutic reagents to macrophages is an effective method for treatment and diagnosis. We previously examined the therapeutic applications of polyrotaxanes (PRXs) comprised of multiple cyclodextrins (CDs) threaded on a polymer chain and capped with bulky stopper molecules. In the present study, we designed an $\alpha$-D-mannose-modified $\alpha$-CD/poly(ethylene glycol)-based PRX (Man-PRX). The intracellular uptake of Man-PRX through the interaction with macrophage mannose receptor (MMR) in macrophage-like RAW264.7 cells was examined. Intracellular Man-PRX uptake was observed in MMR-positive RAW264.7 cells but was negligible in MMR-negative NIH/3T3 cells. In addition, the intracellular Man-PRX uptake in RAW264.7 cells was significantly inhibited in the presence of free $\alpha$-D-mannose and an anti-MMR antibody, which suggests that MMR is involved in the intracellular uptake of Man-PRX. Moreover, the polarization of RAW264.7 cells affected the Man-PRX internalization efficiency. These results indicate that Man-PRX is an effective candidate for selective targeting of macrophages through a specific interaction with the MMR.
\end{abstract}

Keywords: polyrotaxane; cyclodextrin; macrophage; mannose; macrophage mannose receptor

\section{Introduction}

Polyrotaxanes (PRXs) are representative supramolecular polymers comprising multiple cyclodextrins (CDs) threaded along a polymer chain capped with bulky stopper molecules [1-4]. One of the unique characteristics of PRXs is the ability of the mechanically interlocked CDs to freely slide and rotate along the polymer axle. Therefore, the threaded CDs can be immediately released when the bulky terminal stopper molecules are liberated in response to specific stimuli, such as $\mathrm{pH}$, reduction, and light irradiation [5]. Our group had previously developed such stimuli-cleavable PRXs and investigated their applications in biomaterials and drug delivery [4,5]. We recently reported the development of $\beta$-CD-threaded acid-labile PRXs, which can release the $\beta$-CDs in response to the acidic $\mathrm{pH}$ in late endosomes and lysosomes, through acid-induced liberation of bulky stoppers [6-11]. We found that the $\beta$-CDs released from the acid-labile PRXs interact with intracellular cholesterols and lipids by forming an inclusion complex, which leads to the modulation of cellular metabolic functions. 
For example, acid-labile PRXs improve the accumulation of unesterified cholesterol in a cell culture and mouse models of Niemann-Pick type $C$ disease by excreting cholesterols [6-8], promoting the excretion of bisretinoids accumulated in a cell culture model of age-related macular degeneration [9], and inducing autophagy, which is a bulk degradation system for intracellular proteins and organelles, through the induction of endoplasmic reticulum-stress [10]. Since these functions are not observed or are less effective with free CDs, acid-labile PRXs can be potentially applied for treating metabolic diseases such as atherosclerosis [12].

Macrophages play an important role in inflammation, immune system responses, and tissue repair $[13,14]$. Macrophage-induced chronic inflammation is associated with the development of various diseases such as atherosclerosis [15]. Therefore, targeted delivery of PRXs to macrophages is regarded as an effective strategy for preventing and treating various diseases by altering metabolic functions. However, the molecular design of PRXs needs to be improved to achieve macrophage targeting. Macrophages express mannose-binding C-type lectin receptors, such as the macrophage mannose receptor (MMR, also referred to as CD206), which is a $180-\mathrm{kDa}$ transmembrane glycoprotein $[16,17]$. The extracellular region of the MMR contains an N-terminal cysteine-rich domain, a fibronectin type II domain, and eight carbohydrate recognition domains that specifically bind to oligosaccharides, including mannose, fucose, and $\mathrm{N}$-acetylglucosamine [16-18]. Therefore, mannose-conjugation is a promising approach for targeting macrophages through specific recognition by the MMR [18-20]. To date, various mannose-conjugated proteins, polymers, nanoparticles, liposomes, and imaging probes have been developed for treating and diagnosing various diseases, such as cancer, infectious diseases, and metabolic diseases [21-25].

Therefore, we designed mannose-modified PRXs and investigated their ability to modulate anti-inflammatory and proinflammatory cytokine gene expression [26]. However, to date, the ability of mannose-modified PRXs to interact with the MMR and their intracellular uptake in macrophages have not been clarified. In the present study, we synthesized $\alpha$-D-mannose-modified PRX (Man-PRX) and examined its intracellular uptake in macrophage-like RAW264.7 cells in comparison with water-soluble 2-(2-hydroxyethoxy) ethyl (HEE) carbamate-modified PRX (HEE-PRX), which was used in our previous studies [6-9]. In addition, the involvement of MMR in the intracellular uptake of Man-PRX in RAW264.7 cells was investigated using competitive inhibitors or stimulating macrophage polarization to alter the expression level of MMR.

\section{Results and Discussion}

\subsection{Synthesis and Characterization of Man-PRX}

To date, mannose-modified $\alpha$-CD/poly(ethylene glycol) (PEG)-based PRXs or pseudo-PRXs have been synthesized using a click reaction between azidated PRXs and propargyl mannose [26-29]. Although the click reaction is highly efficient for introducing functional molecules on PRXs, it requires the introduction of azide or alkyne groups. In the present study, $\alpha$-D-mannose was chemically modified on the threaded $\alpha$-CDs in PRX by activating the hydroxyl groups of the threaded $\alpha$-CDs with $1,1^{\prime}$-carbonyldiimidazole (CDI) in dimethyl sulfoxide (DMSO), followed by a reaction with 2-aminoethyl $\alpha$-D-mannopyranoside (Man- $\mathrm{NH}_{2}$ ) in the presence of 1,8-diazabicyclo [5.4.0]undec-7-ene (DBU) (Figure 1A) [30,31]. PRX containing $\alpha$-CD as a cyclic molecule, PEG $\left(M_{\mathrm{n}}: 9800\right.$, polymerization degree: 222) as an axle polymer, and adamantyl groups as stopper molecules, was synthesized for the modification of Man- $\mathrm{NH}_{2}$. The number of threaded $\alpha$-CDs and $M_{n}$ of the precursor PRX were determined to be 26.7 (the threading percentage of $\alpha$-CDs in PRX was $24.7 \%$, assuming that one $\alpha-C D$ molecule forms an inclusion complex with two ethylene glycol units in PEG) and 36,100, respectively.

The produced Man-PRX was characterized using size exclusion chromatography (SEC), Fourier transform infrared (FT-IR) spectroscopy, ${ }^{1} \mathrm{H}$ nuclear magnetic resonance (NMR), and ${ }^{13} \mathrm{C}$ NMR. In the SEC charts of Man-PRX, a single unimodal peak was observed $\left(M_{\mathrm{w}} / M_{\mathrm{n}}=1.15\right)$, whereas negligible peaks were detected for free Man- $\mathrm{NH}_{2}, \alpha-\mathrm{CDs}$, and PEG. This indicates that these impurities were 
completely removed during the purification (Figure 2A). In the FT-IR spectrum of Man-PRX, new peaks were observed at 1261, 1538, 1709, and $1755 \mathrm{~cm}^{-1}$, in comparison with unmodified PRX (Figure 2B). These peaks are attributed to the streching vibration of $\mathrm{C}-\mathrm{O}-\mathrm{C}\left(1261 \mathrm{~cm}^{-1}\right)$, the bending vibration of $\mathrm{N}-\mathrm{H}\left(1538 \mathrm{~cm}^{-1}\right)$, and the streching vibration of hydrogen bonded and free $\mathrm{C}=\mathrm{O}(1709$ and $1755 \mathrm{~cm}^{-1}$ ) [32]. These results strongly suggest that Man- $\mathrm{NH}_{2}$ was covalently attached to the hydroxy groups of the threaded $\alpha$-CDs via carbamate linkages.

A

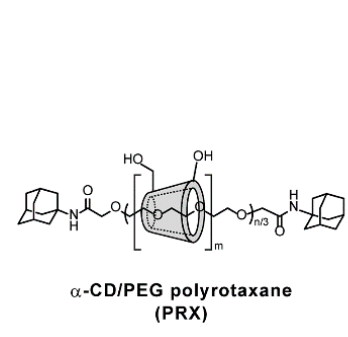

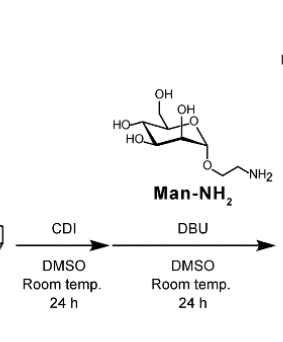

$24 \mathrm{~h}$.

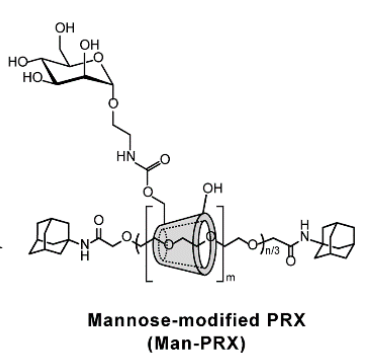

(Man-PRX)

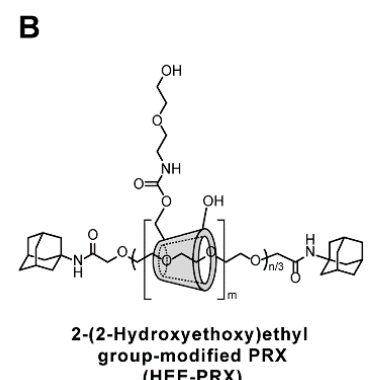

roup-modified PRX
(HEE-PRX)

Figure 1. (A) Scheme for synthesizing $\alpha$-D-mannose-modified $\alpha$-CD/PEG-based PRX (Man-PRX) and (B) chemical structure of 2-(2-hydroxyethoxy)ethyl carbamate-modified PRX (HEE-PRX), where $n$ and $m$ denote the polymerization degree of the PEG axle and the number of threaded $\alpha$-CDs, respectively.

A

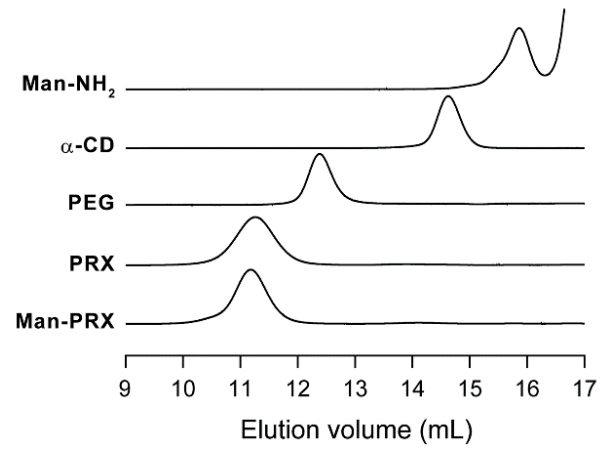

B

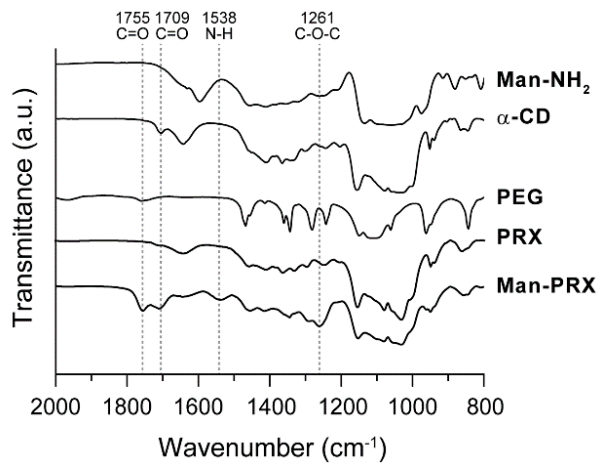

Figure 2. (A) SEC charts of Man- $\mathrm{NH}_{2}, \alpha-\mathrm{CD}$, axle PEG (biscarboxy-PEG, $M_{\mathrm{n}}$ : 9800), unmodified PRX, and Man-PRX in DMSO containing $10 \mathrm{mM} \mathrm{LiBr}$ at $60^{\circ} \mathrm{C}$. (B) FT-IR spectra of Man- $\mathrm{NH}_{2}, \alpha-\mathrm{CD}$, axle PEG, unmodified PRX, and Man-PRX.

In the ${ }^{1} \mathrm{H}$ NMR spectrum of Man-PRX, the peaks of $\alpha$-D-mannose moieties appeared around 4.5-4.7 ppm. However, most of the peaks of Man- $\mathrm{NH}_{2}(3.2-3.8 \mathrm{ppm})$ overlapped with those of threaded $\alpha$-CDs in PRX (Figure 3A). ${ }^{13} \mathrm{C}$ NMR spectrum of Man-PRX clearly showed the new peaks of $\alpha$-D-mannose moieties at 61.2, 67.0, 70.2, 70.8, 71.6, 73.9, and $102.0 \mathrm{ppm}$ (Figure 3B). These results indicate the successful modification of $\alpha$-D-mannose onto PRX. The number of modified $\alpha$-D-mannose molecules in PRX was determined to be 56.5 by comparing the integral ratio between $4.8 \mathrm{ppm}\left(\mathrm{H}_{1}\right.$ proton of threaded $\alpha-\mathrm{CD})$ and 3 to $4 \mathrm{ppm}\left(-\mathrm{CH}_{2}-\mathrm{CH}_{2}-\mathrm{O}\right.$ - of PEG, $\mathrm{H}_{2}, \mathrm{H}_{3}, \mathrm{H}_{4}, \mathrm{H}_{5}$, and $\mathrm{H}_{6}$ protons of threaded $\alpha-\mathrm{CD}, \mathrm{H}_{2}, \mathrm{H}_{3}, \mathrm{H}_{4}, \mathrm{H}_{5}, \mathrm{H}_{6},-\mathrm{O}_{6} \mathrm{H}$, and $-\mathrm{CH}_{2}-\mathrm{CH}_{2}-\mathrm{NH}-\mathrm{C}(=\mathrm{O})$-O-protons of $\alpha$-D-mannose) in the ${ }^{1} \mathrm{H}$ NMR spectrum in $\mathrm{D}_{2} \mathrm{O}$ (data not shown). As a result, the number of modified $\alpha$-D-mannose molecules on PRX and $M_{n}$ of Man-PRX were determined to be 56.5 and 49,800, respectively. The solubility of PRX in aqueous media was remarkably improved by modifying $\alpha$-D-mannose, which results in a solubility of $>130 \mathrm{mg} / \mathrm{mL}$, even though $\alpha$-CD/PEG-based PRXs are generally insoluble in aqueous media because of the formation of intermolecular hydrogen bonds [1,33]. As a control, water-soluble 2-(2-hydroxyethoxy)ethyl carbamate-modified PRX (HEE-PRX), which was designed to solubilize PRXs in water in our previous studies [6-9,30,31], was synthesized using the same PRX (Figure 1B). The number of modified HEE groups in PRX and the $M_{n}$ of HEE-PRX were determined to be 115 and 51,200, respectively. HEE-PRX also showed an excellent solubility in aqueous media $(>150 \mathrm{mg} / \mathrm{mL})$. 
A

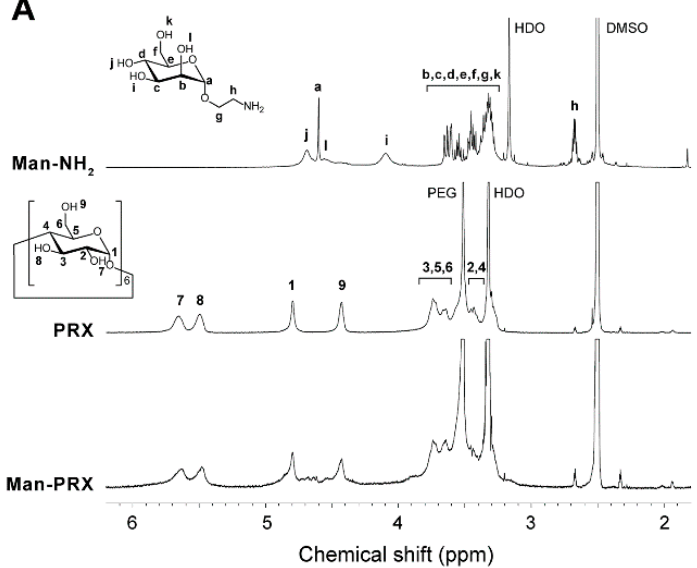

B

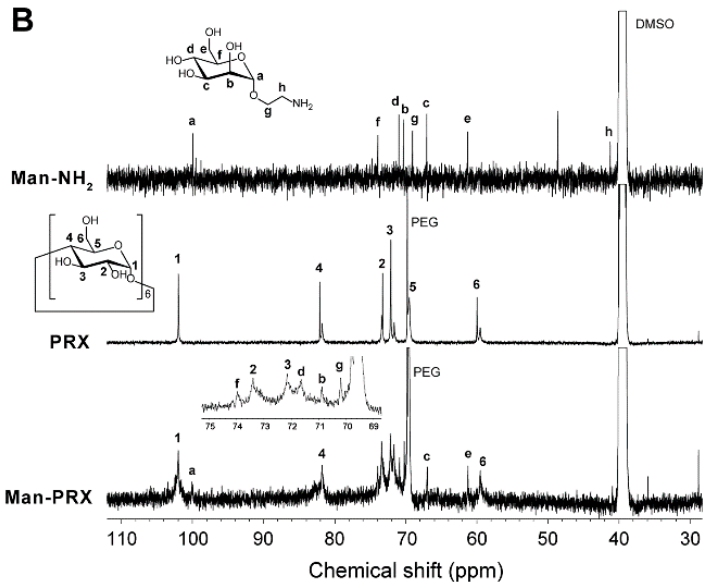

Figure 3. (A) ${ }^{1} \mathrm{H}$ NMR and (B) ${ }^{13} \mathrm{C}$ NMR spectra of Man- $\mathrm{NH}_{2}$, unmodified PRX, and Man-PRX in DMSO- $d_{6}$ at $25^{\circ} \mathrm{C}$.

\subsection{Analysis of the Binding of Man-PRX to the MMR}

The binding affinity of Man-PRX to the MMR was assessed by performing surface plasmon resonance (SPR). The recombinant mouse MMR was immobilized on the SPR sensor chips, and the binding level of Man-PRX to the sensor chips was determined. Figure 4A shows the sensor grams of Man-PRX and HEE-PRX on the MMR-immobilized sensor chip surfaces. We observed that Man-PRX-treated sensor chip surfaces yielded a slightly higher signal (response unit, RU) than HEE-PRX-treated sensor chip surfaces after washing at $180 \mathrm{~s}$. The relationship between PRX concentration and the RU value is shown in Figure 4B. We observed that the RU value of the Man-PRX-treated sensor chip surfaces proportionally increased with an increase in the concentration of Man-PRX. However, the RU value of the HEE-PRX-treated sensor chip surfaces was low even at a HEE-PRX concentration of $10 \mathrm{mg} / \mathrm{mL}$. This result suggests that Man-PRX specifically interacts with the MMR while HEE-PRX barely interact with the MMR. The association and dissociation rate constants between Man-PRX and the MMR were $k_{\mathrm{a}}=1.3 \times 10^{3}\left(\mathrm{M}^{-1} \cdot \mathrm{s}^{-1}\right)$ and $k_{\mathrm{d}}=1.4\left(\mathrm{~s}^{-1}\right)$. The dissociation constant between Man-PRX and the MMR was $K_{D}=1.0 \times 10^{-3}(\mathrm{M})$, which is remarkably higher than the value reported in a previous study $(10 \mathrm{nM})$ [18]. In our previous study, the association rate constant was affected by the density of proteins immobilized on the SPR sensor chip and the number of modified mannose molecules on PRX [28]. We concluded that the number of $\alpha$-D-mannose molecules in Man-PRX or the density of the MMR on the sensor chips was insufficient to show a low dissociation constant.
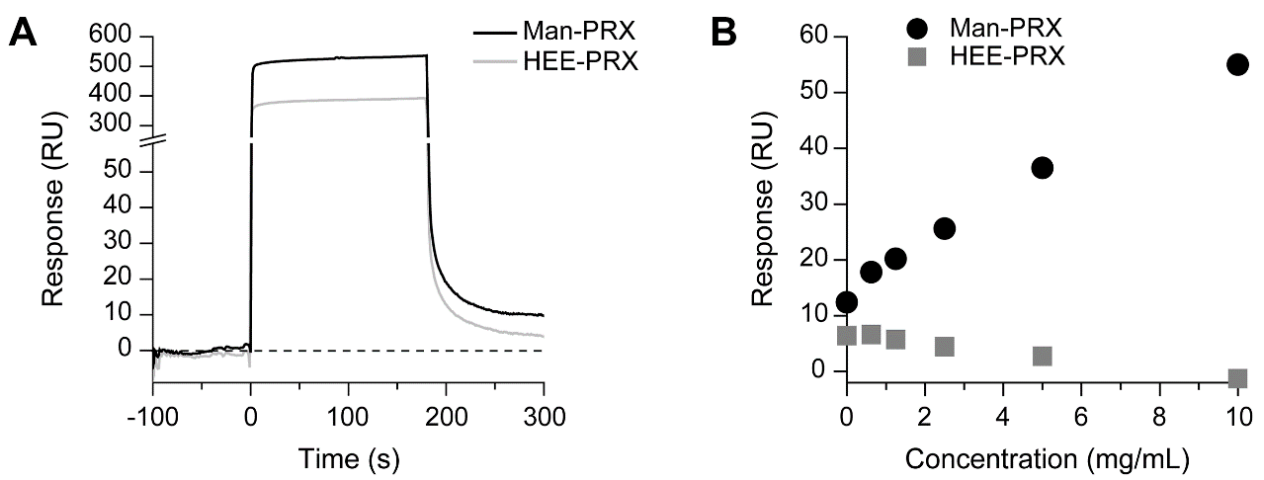

Figure 4. (A) SPR sensor grams of Man-PRX ( $5 \mathrm{mg} / \mathrm{mL})$ and HEE-PRX ( $5 \mathrm{mg} / \mathrm{mL})$ on the mouse MMR-immobilized sensor chip surfaces. (B) Relationship between PRX concentration and the SPR response. The circles and squares in the plot indicate Man-PRX and HEE-PRX, respectively. 


\subsection{Intracellular Man-PRX Uptake in RAW264.7 Cells}

To clarify the effect of $\alpha$-D-mannose modification on the intracellular uptake of Man-PRX through the MMR, we assessed the intracellular uptake of Man-PRX in RAW264.7 cells (mouse macrophage-like cells) because they exhibit a high MMR expression [34]. As a control, NIH/3T3 (mouse fibroblasts) cells were used as MMR-negative cells [35]. The flow cytometric analysis of MMR using allophycocyanin (APC)-conjugated anti-MMR antibody revealed that MMR expression was not observed in NIH/3T3 cells, but was significant in RAW264.7 cells (Figure 5A,B). To evaluate the intracellular Man-PRX uptake by flow cytometry and confocal laser scanning microscopy (CLSM), BODIPY FL fluorescent molecules were modified onto Man-PRX (BODIPY-Man-PRX) because of their high molar absorption coefficient, high fluorescence quantum yield, and insensitivity to solvent polarity and $\mathrm{pH}$ [36]. BODIPY-labeled HEE-PRX (BODIPY-HEE-PRX) was also prepared as a control. First, we investigated the time-course of intracellular uptake of BODIPY-Man-PRX and BODIPY-HEE-PRX by performing flow cytometry (Figure 5C,D). The intracellular uptake of BODIPY-Man-PRX and BODIPY-HEE-PRX was comparable in the MMR-negative NIH/3T3 cells after $24 \mathrm{~h}$ of incubation. In contrast, the intracellular uptake of BODIPY-Man-PRX was significantly higher than that of BODIPY-HEE-PRX in the MMR-positive RAW264.7 cells.

A

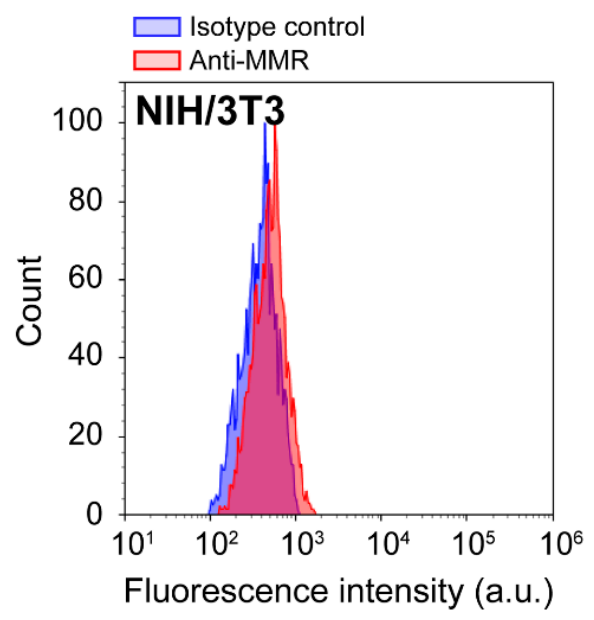

C

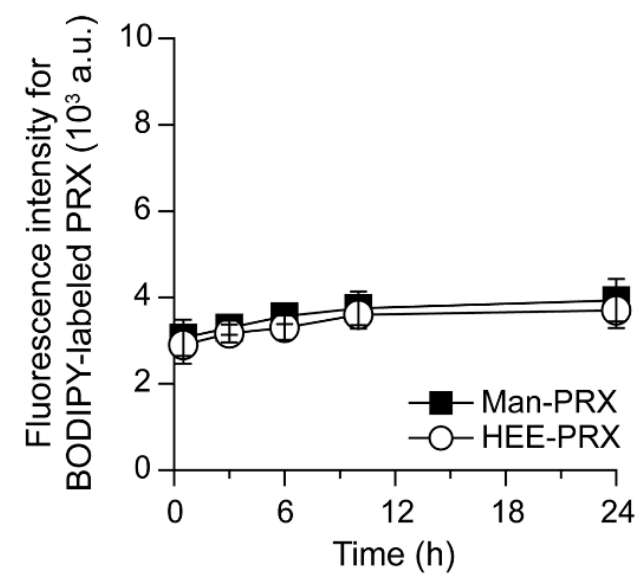

B

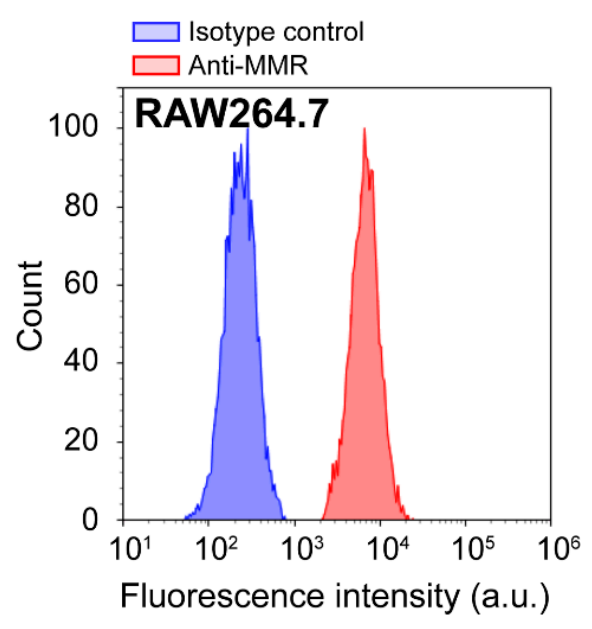

D

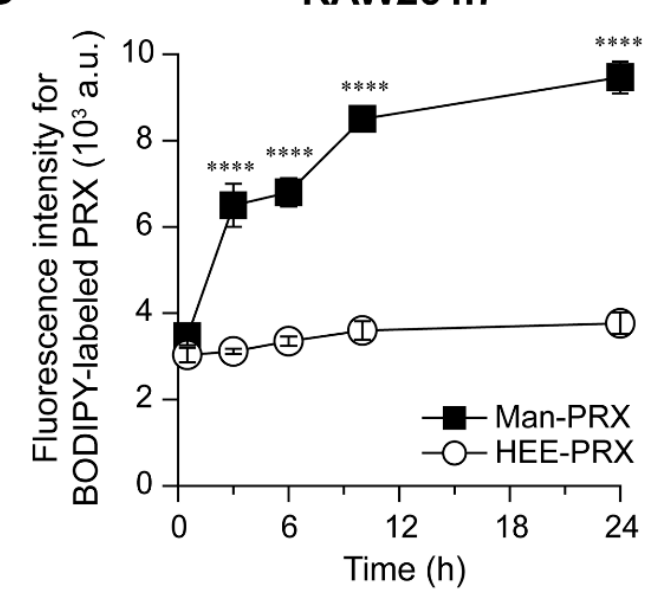

Figure 5. Fluorescence intensities of (A) NIH/3T3 and (B) RAW264.7 cells treated with the APC-labeled IgG2a, $\mathrm{K}$ isotype control and APC-anti-MMR antibody. The time course of fluorescence intensity of (C) NIH/3T3 and (D) RAW264.7 cells treated with BODIPY-HEE-PRX (10 $\mu \mathrm{M}$, open circles) and BODIPY-Man-PRX (10 $\mu \mathrm{M}$, closed squares). Data are expressed as mean \pm standard deviation $(\mathrm{n}=3$, $* * * * 0<0.001)$. 
Next, we evaluated the intracellular distribution of BODIPY-Man-PRX in the MMR-positive RAW264.7 cells by performing CLSM (Figure 6). To visualize the localization, the cell nuclei and late endosomes/lysosomes were stained with Hoechst 33,342 and LysoTracker Red, respectively. The fluorescence signals of BODIPY-HEE-PRX were not observed after $3 \mathrm{~h}$ and $24 \mathrm{~h}$ of incubation. In contrast, the fluorescence signals of BODIPY-Man-PRX were clearly observed after $3 \mathrm{~h}$ of incubation, which was consistent with the results of flow cytometry. At $3 \mathrm{~h}$ of incubation, BODIPY-Man-PRX was found to be co-localized with late endosomes/lysosomes, which indicates that BODIPY-Man-PRX was internalized in RAW264.7 cells through endocytosis. Image analysis showed that the co-localization percentage of BODIPY-Man-PRX with LysoTracker Red was 76.1\% after $3 \mathrm{~h}$ and $52.5 \%$ after $24 \mathrm{~h}$ of incubation. This result indicates that Man-PRX was transferred to other organelles or reached the cytoplasm. However, the detailed underlying mechanisms are unclear.

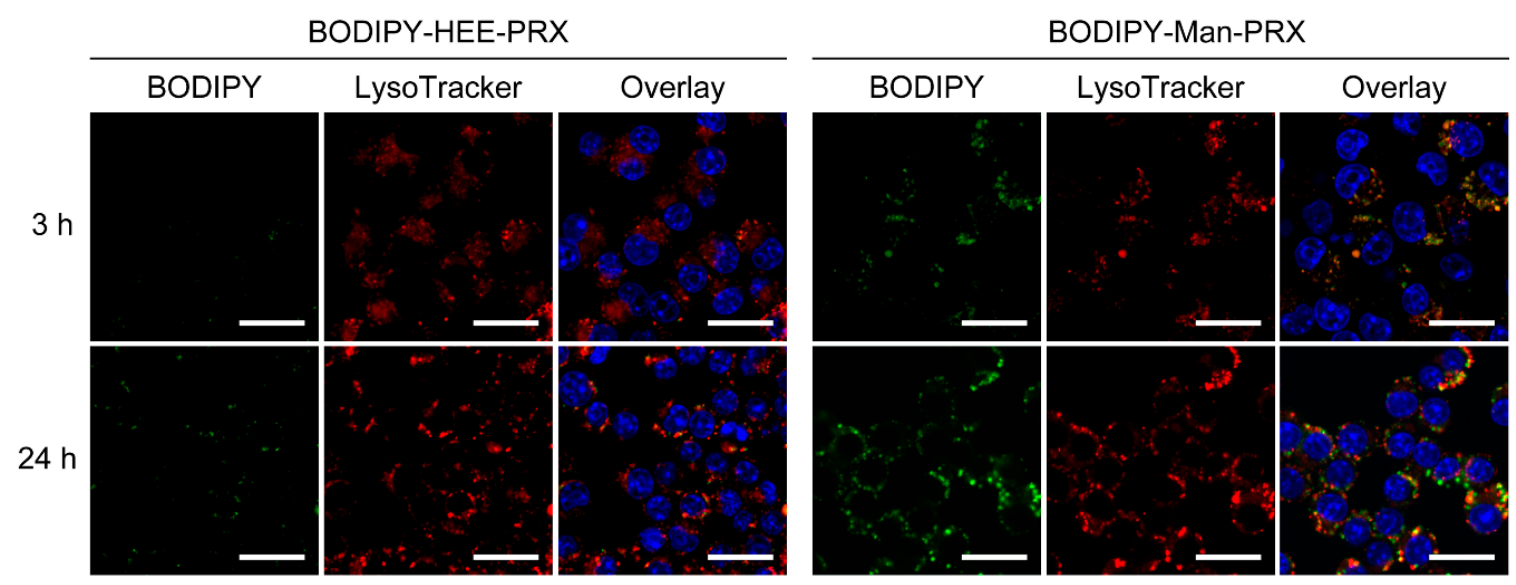

Figure 6. CLSM images of RAW264.7 cells treated with BODIPY-HEE-PRX (10 $\mu \mathrm{M}$, green, first row) and BODIPY-Man-PRX (10 $\mu \mathrm{M}$, green, first row) for $3 \mathrm{~h}$ and $24 \mathrm{~h}$ (scale bars: $20 \mu \mathrm{m})$. The cells were stained with Hoechst 33,342 (blue) and LysoTracker Red (red, second row) to visualize the cell nuclei and lysosomes, respectively. The third row depicts overlay images.

To verify the involvement of the MMR on the intracellular BODIPY-Man-PRX uptake in RAW264.7 cells, the intracellular BODIPY-Man-PRX uptake was competitively inhibited using free $\alpha$-D-mannose (Figure 7A) [21]. The intracellular BODIPY-Man-PRX uptake reduced with an increase in the concentration of free $\alpha$-D-mannose in the culture medium. The significant inhibition of Man-PRX uptake was observed when the free $\alpha$-D-mannose concentration was higher than the concentration of modified $\alpha$-D-mannose in Man-PRX. This result suggests that the modified $\alpha$-D-mannose in Man-PRX plays an essential role in the intracellular uptake of PRXs in MMR-positive RAW264.7 cells. Similarly, RAW264.7 cells were pretreated with anti-MMR antibody to mask the MMR. The intracellular BODIPY-Man-PRX uptake decreased upon pre-treatment with the anti-MMR antibody (Figure 7B). Although the binding sites of mannose and anti-MMR antibody may be different, it was considered that large antibody molecules sterically inhibited the interaction between Man-PRX and MMR on the surface of the cells. According to these results, the MMR was involved in the intracellular uptake of Man-PRX in RAW264.7 cells.

\subsection{Effect of RAW264.7 Cell Polarization on the Intracellular Man-PRX Uptake}

Macrophages perform different functions upon stimulation with various factors. Lipopolysaccharide (LPS) and interferon (IFN)- $\gamma$ polarize macrophages toward the M1 phenotype [37,38], which are characterized by the secretion of proinflammatory cytokines and the expression of major histocompatibility complex class II and co-stimulatory molecules, in order to initiate and sustain inflammation. In contrast, interleukin (IL)-4 polarizes macrophages toward the M2 phenotype, which is characterized by the secretion of anti-inflammatory cytokines, in order 
to resolve inflammation and initiatetissue repair [37,38]. Note that the MMR expression level was increased in M2 macrophages. Therefore, it was concluded that the intracellular Man-PRX uptake might be affected by macrophage polarization.
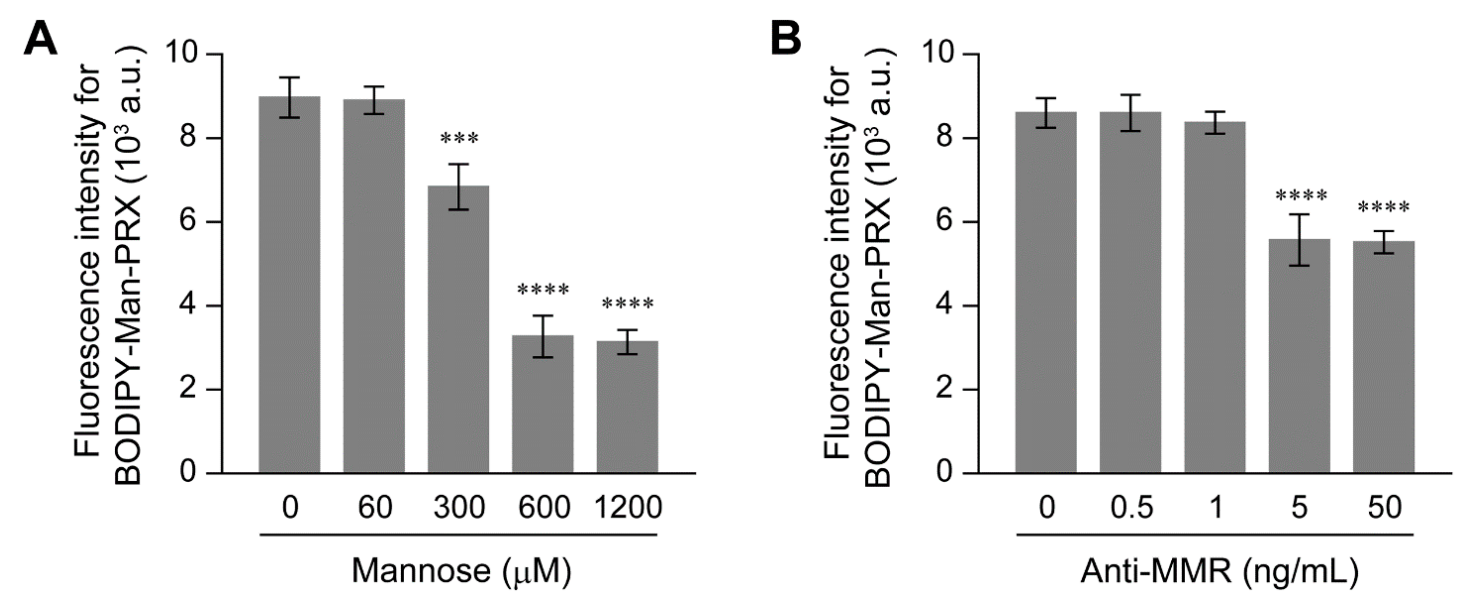

Figure 7. Fluorescence intensity of RAW 264.7 cells pretreated with various concentrations of (A) $\alpha$-D-mannose and (B) anti-MMR antibody for $3 \mathrm{~h}$, followed by treatment with BODIPY-Man-PRX for $3 \mathrm{~h}$. The concentration of BODIPY-Man-PRX was $10 \mu \mathrm{M}$, which corresponded to $565 \mu \mathrm{M} \alpha$-D-mannose molecules modified on PRX. Data are expressed as mean \pm standard deviation $\left(n=3,{ }^{* * *} p<0.005\right.$ and $* * * * p<0.001)$.

To investigate the effect of RAW264.7 cell polarization on the intracellular Man-PRX uptake, RAW264.7 cells were stimulated with LPS and IFN- $\gamma$ to polarize them toward the M1 phenotype, or with IL-4 to polarize them toward the M2 phenotype. In the present study, the phenotype of the untreated cells was denoted as M0. The phenotype of RAW264.7 cells was characterized by evaluating the gene expression levels of the tumor necrosis factor (TNF)- $\alpha$ and IL-6 as a marker of M1 polarization, and arginase-1 (Arg-1) as a marker of M2 polarization (Figure 8A) [37,39]. RAW264.7 cells treated with LPS and IFN- $\gamma$ showed significantly increased TNF- $\alpha$ and IL-6 expression levels while those treated with IL-4 showed significantly increased Arg-1 expression levels, when compared with untreated cells. Next, the effect of macrophage polarization on the MMR expression level was investigated (Figure 8B,C). The MMR expression level was upregulated in M2 macrophages, but significantly downregulated in M1 macrophages, compared with the M0 macrophages, which is consistent with previous reports $[40,41]$. These results indicate a successful polarization of RAW264.7 cells in the M1 and M2 phenotypes.

The effect of RAW264.7 cell polarization on the intracellular uptake of Man-PRX and HEE-PRX was evaluated using flow cytometry (Figure 8D). In addition, we observed that, compared with the M0 macrophages, the intracellular BODIPY-Man-PRX uptake increased in M2 macrophages and decreased in M1 macrophages. However, the intracellular BODIPY-HEE-PRX uptake was similar across all three macrophage polarization states. This result suggests that the MMR expression level is an important factor for determining the intracellular Man-PRX uptake, and that Man-PRX is preferentially internalized in M2 macrophages via MMR-mediated endocytosis. 
A $\begin{aligned} & \text { Control (M0) } \\ & \text { LPS + IFN-y (M1) } \\ & \square \text { IL-4 (M2) }\end{aligned}$

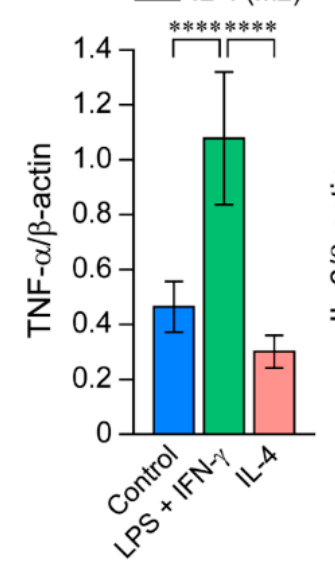

C

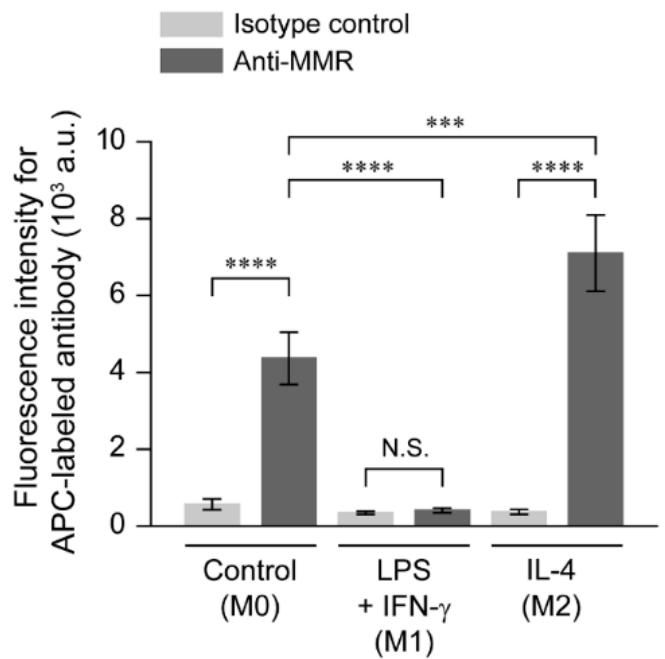

B

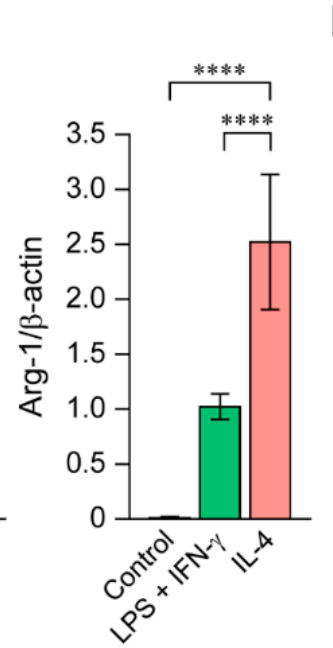

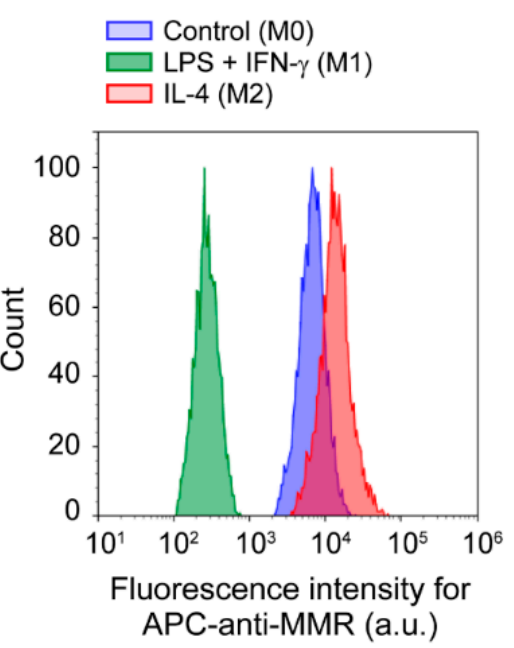

D

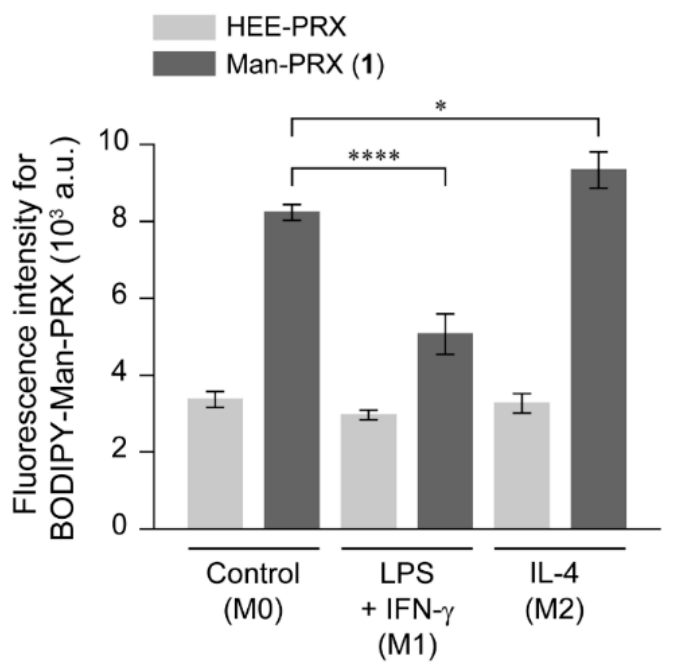

Figure 8. (A) mRNA expression levels of TNF- $\alpha$, IL-6, and Arg-1 in RAW 264.7 cells polarized with LPS (100 ng/mL) + IFN- $\gamma(100 \mathrm{ng} / \mathrm{mL})$ (M1 polarization), or IL-4 (400 ng/mL) (M2 polarization), for $24 \mathrm{~h}$. The phenotype of untreated RAW264.7 cells was denoted as M0. The expression levels of each gene were normalized by the expression level of the $\beta$-actin gene $(n=4)$. $(B, C)$ The fluorescence intensity of RAW264.7 cells polarized with LPS + IFN- $\gamma$ or IL- 4 for $24 \mathrm{~h}$, followed by treatment with the APC-labeled IgG2a, $\mathrm{k}$ isotype control and APC-anti-MMR antibody $(\mathrm{n}=3)$. (D) The fluorescence intensity of RAW264.7 cells polarized with LPS + IFN- $\gamma$ or IL-4 for $24 \mathrm{~h}$ was followed by treatment with BODIPY-HEE-PRX $(10 \mu \mathrm{M})$ and BODIPY-Man-PRX $(10 \mu \mathrm{M})$ for $3 \mathrm{~h}$. Data are expressed as mean \pm standard deviation $\left(\mathrm{n}=3,{ }^{*} p<0.05,{ }^{* * *} p<0.005\right.$, and ${ }^{* * * *} p<0.001$. N.S. indicates no significance).

\section{Materials and Methods}

\subsection{Materials}

PRX containing $\alpha$-CD as a cyclic molecule, PEG $\left(M_{n}: 9800\right.$, polymerization degree: 222$)$ as an axle polymer, and adamantyl groups as stopper molecules, was synthesized in accordance with a previous study [42]. In addition, Man- $\mathrm{NH}_{2}$ and HEE-PRX $\left(M_{n}\right.$ of PEG axle: 9800 , number of threaded $\alpha$-CDs: 26.7, number of HEE groups modified on PRX: 115, $\left.M_{n}: 51,200\right)$ were also synthesized in accordance with previous studies $[30,31,43]$. 


\subsection{Instrumentation}

${ }^{1} \mathrm{H}$ NMR and ${ }^{13} \mathrm{C}$ NMR spectra were recorded in DMSO- $d_{6}$ at $25{ }^{\circ} \mathrm{C}$, using a Bruker Avance III $400 \mathrm{MHz}$ spectrometer (Bruker BioSpin, Rheinstetten, Germany). Chemical shifts in ${ }^{1} \mathrm{H}$ NMR and ${ }^{13} \mathrm{C}$ NMR spectra were referenced using tetramethylsilane (0 ppm) and DMSO (39.5 ppm), respectively. SEC was performed using Prominence-i LC-2030 Plus (Shimadzu, Kyoto, Japan) equipped with an RID-20A refractive index detector (Shimadzu) and a combination of TSKgel $\alpha-4000$ and $\alpha-2500$ columns (300 mm length, $7.8 \mathrm{~mm}$ internal diameter) (Tosoh, Tokyo, Japan). Sample solutions were injected into the system and then eluted with DMSO containing $10 \mathrm{mM} \mathrm{LiBr}$ at a flow rate of $0.35 \mathrm{~mL} / \mathrm{min}$ at $60{ }^{\circ} \mathrm{C}$. The polydispersity index $\left(M_{\mathrm{w}} / M_{\mathrm{n}}\right)$ was calculated using a calibration curve of standard PEG (Agilent Technologies, Wilmington, DE, USA).

\subsection{Synthesis of Man-PRX}

PRX $\left(M_{n}\right.$ of the PEG axle: 9800, number of threaded $\alpha$-CDs: $26.7, M_{n}$ of PRX: 36,100) $(300 \mathrm{mg}$, $8.31 \mu \mathrm{mol}$ PRX, $222 \mu \mathrm{mol}$ threaded $\alpha$-CDs in PRX) and CDI (358 mg, $2.21 \mathrm{mmol}$, Merck, Darmstadt, Germany) were dissolved in dehydrated DMSO (30 mL, Kanto Chemicals, Tokyo, Japan) under a nitrogen atmosphere, and. the solution was stirred for $24 \mathrm{~h}$ at room temperature. DBU (1.32 mL, $8.88 \mathrm{mmol}$, Merck) and Man- $\mathrm{NH}_{2}(1.97 \mathrm{~g}, 8.82 \mathrm{mmol})$ were added to the reaction mixture, and the solution was stirred for $24 \mathrm{~h}$ at room temperature. The resulting solution was purified by dialysis against water for 3 days by using Spectra/Por 4 (molecular weight cut-off [MWCO]: 12,000-14,000, Spectrum Laboratories, Rancho Dominguez, CA, USA). The recovered solution was freeze-dried to yield Man-PRX (331 mg 80.0\% yield). ${ }^{1} \mathrm{H}$ NMR (400 MHz, DMSO- $\left.d_{6}\right): \delta=1.62$ (m, adamantyl group), 1.93 (m, adamantyl group), 2.03 (m, adamantyl group), 3.06-4.01 (m, $-\mathrm{CH}_{2}-\mathrm{CH}_{2}-\mathrm{O}-\mathrm{of} \mathrm{PEG}$, $\mathrm{H}_{2}, \mathrm{H}_{3}, \mathrm{H}_{4}, \mathrm{H}_{5}$, and $\mathrm{H}_{6}$ protons of $\alpha-\mathrm{CD}$, and $\mathrm{H}_{2}, \mathrm{H}_{3}, \mathrm{H}_{4}, \mathrm{H}_{5}, \mathrm{H}_{6},-\mathrm{O}_{6} \mathrm{H}$, and $-\mathrm{CH}_{2}-\mathrm{CH}_{2}-\mathrm{NH}-\mathrm{C}(=\mathrm{O})-\mathrm{O}-$ protons of $\alpha$-D-mannose), $4.42\left(\mathrm{~m},-\mathrm{O}_{6} \mathrm{H}\right.$ proton of $\left.\alpha-\mathrm{CD}\right), 4.59-4.74\left(\mathrm{~m}, \mathrm{H}_{1},-\mathrm{O}_{2} \mathrm{H}\right.$, and $-\mathrm{O}_{4} \mathrm{H}$ protons of $\alpha$-D-mannose), $4.79\left(\mathrm{~m}, \mathrm{H}_{1}\right.$ proton of $\alpha$-CD), 5.48 (m, $-\mathrm{O}_{3} \mathrm{H}$ proton of $\left.\alpha-\mathrm{CD}\right), 5.63\left(\mathrm{~m},-\mathrm{O}_{2} \mathrm{H}\right.$ proton of $\alpha-\mathrm{CD}) .{ }^{13} \mathrm{C}$ NMR $\left(100 \mathrm{MHz}, \mathrm{DMSO}-\alpha_{6}\right): \delta=59.5\left(\mathrm{C}_{6}\right.$ of $\left.\alpha-\mathrm{CD}\right), 61.2\left(\mathrm{C}_{6}\right.$ of $\alpha$-D-mannose), $67.0\left(\mathrm{C}_{3}\right.$ of $\alpha$-D-mannose), 69.7 (- $\mathrm{CH}_{2}-\mathrm{CH}_{2}-\mathrm{O}$ - of PEG and $\mathrm{C}_{5}$ of $\left.\alpha-\mathrm{CD}\right), 70.2\left(-\mathrm{CH}_{2}-\mathrm{CH}_{2}-\mathrm{NH}-\mathrm{C}(=\mathrm{O})-\mathrm{O}-\right.$ protons of $\alpha$-D-mannose), 70.8 ( $C_{2}$ of $\alpha$-D-mannose), 71.6 ( $\mathrm{C}_{4}$ of $\alpha$-D-mannose), $72.1\left(\mathrm{C}_{3}\right.$ of $\alpha$-CD), 73.4 ( $\mathrm{C}_{2}$ of $\alpha-C D), 73.9\left(C_{5}\right.$ of $\alpha$-D-mannose), $81.7\left(C_{4}\right.$ of $\left.\alpha-C D\right), 100.0\left(C_{1}\right.$ of $\left.\alpha-C D\right)$, and $102.0\left(C_{1}\right.$ of $\alpha$-D-mannose).

\subsection{Synthesis of BODIPY-Labeled PRX}

Man-PRX (100 mg, $2.01 \mu \mathrm{mol}$ PRX, $53.6 \mu \mathrm{mol}$ threaded $\alpha$-CDs in PRX) and CDI (38.2 mg, $236 \mu \mathrm{mol})$ were dissolved in dehydrated DMSO $(5 \mathrm{~mL})$ under a nitrogen atmosphere and the solution was stirred for $6 \mathrm{~h}$ at room temperature. 4,4-Difluoro-5,7-dimethyl-4-bora-3a,4a-diaza-s-indacene-3-propionyl ethylenediamine hydrochloride (BODIPY FL EDA; Thermo Fisher Scientific, Waltham, MA, USA) $(1.02 \mathrm{mg}, 2.75 \mu \mathrm{mol})$ was added to the reaction mixture, and the solution was stirred for $24 \mathrm{~h}$ at room temperature, with protection from light. After the reaction, the resulting polymer was purified by dialysis against water for 3 days using Spectra/Por 4 (MWCO: 12,000-14,000), and the recovered solution was freeze-dried to yield BODIPY-labeled Man-PRX (BODIPY-Man-PRX) (99.4 mg). The number of BODIPY molecules modified onto Man-PRX was determined by measuring the absorbance at $503 \mathrm{~nm}$ (one BODIPY molecule was modified onto 6.3 Man-PRX molecules). BODIPY-labeled HEE-PRX (BODIPY-HEE-PRX) was synthesized and characterized in the same manner. In subsequent experiments, unlabeled and BODIPY-labeled PRXs were mixed to adjust the fluorescence intensities of BODIPY-Man-PRX and BODIPY-HEE-PRX.

\subsection{Analysis of the Binding between Man-PRX and the MMR by SPR}

When performing SPR, the MMR was immobilized on a sensor chip using a previously described protocol [44,45]. Briefly, CM5 sensor chips (GE Healthcare, Chicago, IL, USA), with a carboxymethylated dextran-immobilized gold surface, were treated with a buffer solution 
containing 10 mM 2-[4-(2-hydroxyethyl)piperazin-1-yl]ethanesulfonic acid (HEPES), $200 \mathrm{mM}$ 1-ethyl-3-(3-dimethylaminopropyl)carbodiimide hydrochloride, and $50 \mathrm{mM}$ N-hydroxysuccinimide at a flow rate of $5 \mu \mathrm{L} / \mathrm{min}$, in a Biacore X100 instrument (GE Healthcare). Next, recombinant mouse MMR (R \& D Systems, Minneapolis, MN, USA) $(15.4 \mu \mathrm{g} / \mathrm{mL})$ was immobilized on the activated CM5 sensor chips in $10 \mathrm{mM}$ sodium acetate buffer ( $\mathrm{pH}$ 5.5) with a flow rate of $5 \mu \mathrm{L} / \mathrm{min}$ at $25^{\circ} \mathrm{C}$ for $1080 \mathrm{~s}$. The response unit (RU) of the MMR in this condition was approximately 6,000 RU. The binding affinity of Man-PRX and HEE-PRX toward the MMR-immobilized sensor chip surfaces was analyzed by dissolving different concentrations of Man-PRX and HEE-PRX in a buffer solution containing $10 \mathrm{mM}$ HEPES, $150 \mathrm{mM} \mathrm{NaCl}, 3 \mathrm{mM}$ EDTA, 0.005\% surfactant P20, $1 \mathrm{mM} \mathrm{CaCl}_{2}$, and $1 \mathrm{mM} \mathrm{MgCl}$, which was followed by treatment of the MMR-immobilized sensor chip surfaces with the PRX solutions at a flow rate of $30 \mu \mathrm{L} / \mathrm{min}$ at $25^{\circ} \mathrm{C}$ for $180 \mathrm{~s}$. The calibrated sensorgrams were fitted to a Langmuir $1: 1 \mathrm{binding}$ model, and the kinetic parameters were determined using Biacore X100 Evaluation Software (version 2.0.1, GE Healthcare) [28].

\subsection{Cell Culture}

RAW264.7 cells, a mouse macrophage-like cell line, and NIH/3T3 cells, a mouse embryonic fibroblast cell line, were obtained from the American Type Culture Collection (ATCC, Manassas, VA, USA) and the Japanese Collection of Research Bioresources (JCRB, Osaka, Japan), respectively. Both the cell lines were cultured in Dulbecco's modified Eagle's medium (DMEM) (Fujifilm Wako Pure Chemical, Osaka, Japan) supplemented with 10\% fetal bovine serum (Gibco, Grand Island, NY, USA), 100 units/mL penicillin (Fujifilm Wako Pure Chemical), and $100 \mu \mathrm{g} / \mathrm{mL}$ streptomycin (Fujifilm Wako Pure Chemical) in $5 \% \mathrm{CO}_{2}$ at $37^{\circ} \mathrm{C}$.

\subsection{Expression Level of the $M M R$}

NIH/3T3 or RAW264.7 cells cultured in 24-well plates (Thermo Fisher Scientific) were harvested and collected by centrifugation at $350 \times g$ and $4{ }^{\circ} \mathrm{C}$ for $5 \mathrm{~min}$. The RAW264.7 cells were treated with TruStain FcX (anti-mouse CD16/32 antibody, clone: 93, BioLegend, San Diego, CA, USA) for 15 min at $4{ }^{\circ} \mathrm{C}$ to block FC $\gamma$ receptors III and II. Next, the cells were stained with APC-labeled anti-mouse MMR (APC-MMR) antibody (clone: C068C2, Biolegend) or APC-labeled mouse IgG2a, $\mathrm{k}$ isotype control antibodies (clone: MOPC-173, Biolegend) for $10 \mathrm{~min}$ at $4{ }^{\circ} \mathrm{C}$. The cells were then collected by centrifugation at $350 \times g$ and $4{ }^{\circ} \mathrm{C}$ for $5 \mathrm{~min}$, washed with phosphate buffered saline containing $0.1 \%$ bovine serum albumin, and passed through a $35-\mu \mathrm{m}$ cell strainer (Corning, Corning, NY, USA). The fluorescence intensity of the cells was measured using a NovoCyte 2000 flow cytometer (ACEA Biosciences, San Diego, CA, USA). The APC-MMR antibody-stained cells were excited using a 640-nm laser and detected using a $675 \pm 30-\mathrm{nm}$ bandpass filter. In all, 10,000 cells were counted for each sample, and the fluorescence intensity of the cell population was determined using Novo Express software (version 1.2.5, ACEA Biosciences).

\subsection{Flow Cytometry Analysis of Intracellular Man-PRX Uptake}

NIH/3T3 or RAW264.7 cells were plated in 24-well plates $\left(5 \times 10^{4}\right.$ cells/well) and incubated overnight. The cells were then cultured in a treatment medium containing BODIPY-Man-PRX and BODIPY-HEE-PRX $\left(10 \mu \mathrm{M}\right.$ PRX) at $37^{\circ} \mathrm{C}$ for the prescribed durations. Subsequently, the cells were harvested, and their fluorescence intensity was measured using a NovoCyte 2000 flow cytometer. The BODIPY-labeled PRX-treated cells were excited using a 488-nm laser and detected using a 530 \pm 30-nm bandpass filter. The fluorescence intensity of the treated cells was analyzed as described above.

\subsection{Inhibition of Intracellular Man-PRX Uptake}

RAW264.7 cells were plated in 24 -well plates $\left(5 \times 10^{4}\right.$ cells / well $)$ and incubated overnight. The cells were then cultured in a medium containing different concentrations of $\alpha$-D-mannose (Fujifilm Wako Pure Chemical) or anti-MMR antibody at $37^{\circ} \mathrm{C}$ for $3 \mathrm{~h}$. Next, the medium was replaced with a 
treatment medium containing BODIPY-Man-PRX (10 $\mu \mathrm{M}$ PRX), and the cells were cultured for $3 \mathrm{~h}$ at $37^{\circ} \mathrm{C}$. Lastly, the cells were harvested, and their fluorescence intensity was measured based on the description above.

\subsection{CLSM Observation}

RAW264.7 cells were plated in a 35-mm glass bottom dish (diameter of glass area: $12 \mathrm{~mm}$ ) (Iwaki, Tokyo, Japan) at a density of $5 \times 10^{4}$ cells / dish and incubated overnight. Next, the cells were cultured in a treatment medium containing BODIPY-Man-PRX or BODIPY-HEE-PRX (10 $\mu$ M PRX) for 3 or $24 \mathrm{~h}$. The cells were then stained with $500 \mathrm{nM}$ LysoTracker Red DND-99 (Thermo Fisher Scientific) at $37^{\circ} \mathrm{C}$ for $15 \mathrm{~min}$, followed by staining with $1 \mu \mathrm{g} / \mathrm{mL}$ Hoechst 33,342 (Dojindo Laboratories, Kumamoto, Japan) at $37^{\circ} \mathrm{C}$ for $10 \mathrm{~min}$. CLSM observation was performed using FluoView FV10i (Olympus, Tokyo, Japan) equipped with a $60 \times$ water-immersion objective lens (numerical aperture 1.2). The excitation and emission wavelengths for Hoechst 33342, BODIPY-labeled PRXs, and LysoTracker Red were $405 \mathrm{~nm}$ and $455 \mathrm{~nm}, 473 \mathrm{~nm}$ and $520 \mathrm{~nm}$, and $559 \mathrm{~nm}$ and $598 \mathrm{~nm}$, respectively. The colocalization percentage was determined according to a previously reported method [46]. The values of the co-localization percentage are expressed as mean \pm standard deviation of 100 cells.

\subsection{Effect of RAW264.7 Cell Polarization on the Intracellular Man-PRX Uptake}

RAW264.7 cells were plated in 24 -well plates $\left(5 \times 10^{4}\right.$ cells/well $)$ and incubated overnight. The cells were then polarized for $24 \mathrm{~h}$ at $37^{\circ} \mathrm{C}$ using $100 \mathrm{ng} / \mathrm{mL}$ LPS (Fujifilm Wako Pure Chemical) and $100 \mathrm{ng} / \mathrm{mL}$ recombinant mouse IFN- $\gamma$ (PeproTech, Rocky Hill, NJ, USA) to produce the M1 phenotype, or $400 \mathrm{ng} / \mathrm{mL}$ recombinant mouse IL-4 (PeproTech) to produce the M2 phenotype. The expression level of MMR was determined as described above. Next, the medium was replaced with a treatment medium containing BODIPY-Man-PRX (10 $\mu \mathrm{M}$ PRX), and the cells were cultured for $3 \mathrm{~h}$ at $37^{\circ} \mathrm{C}$. Lastly, the cells were harvested, and their fluorescence intensity was measured as described above.

\subsection{Quantitative RT-PCR}

RAW264.7 cells were plated in six-well plates $\left(1 \times 10^{6}\right.$ cells/well $)$ and incubated overnight. Next, the cells were polarized as described above. Total RNA was isolated from the cells using the RNeasy Mini Kit (Qiagen, Valencia, CA, USA), and the cDNA was synthesized using the iScript Advanced cDNA Synthesis Kit (Bio-Rad, Hercules, CA, USA). Next, a reaction mixture containing cDNA $(2 \mu \mathrm{L})$, forward and reverse primers $(0.8 \mu \mathrm{L}$ final concentration: $4 \mu \mathrm{M})$, and SsoAdvanced SYBR Green Supermix (Bio-Rad) $(10 \mu \mathrm{L})$ was prepared, and its volume was adjusted to $20 \mu \mathrm{L}$ using RNase/DNase-free water. Quantitative RT-PCR was performed using the CFX Connect Real Rime PCR System (Bio-Rad) with the following thermal cycling conditions: 45 cycles of denaturation at $95^{\circ} \mathrm{C}$ for $5 \mathrm{~s}$, annealing at $58^{\circ} \mathrm{C}$ for $10 \mathrm{~s}$, and extension at $72{ }^{\circ} \mathrm{C}$ for $10 \mathrm{~s}$. The sequences of the primer sets were as follows: mouse TNF- $\alpha$, forward: $5^{\prime}$-CAT CTT CTC AAA ATT CGA GTG ACA A- $3^{\prime}$, reverse: 5'-TGG GAG TAG ACA AGG TAC AAC CC-3'; mouse IL-6, forward: 5'-GAG GAT ACC ACT CCC AAC AGA CC-3', reverse: 5'-AAG TGC ATC ATC GTT GTT CAT ACA-3'; mouse Arg-1, forward: 5'-CAT TGG CTT GCG AGA CGT AGA C-3', reverse: 5'-GCT GAA GGT CTC TTC CAT CAC C-3' and $\beta$-actin forward: $5^{\prime}$-GGC TGT ATT CCC CTC CAT CG-3', reverse: $5^{\prime}$-CCA GTT GGT AAC AAT GCC ATG T-3'. The gene expression levels were calculated using the $\Delta \Delta \mathrm{Ct}$ method and normalized using the expression level of the $\beta$-actin gene.

\subsection{Statistical Analysis}

Statistical analyses were performed using OriginPro 8 (OriginLab, Northampton, MA, USA). Data from more than three groups were compared using one-way analysis of variance (ANOVA) followed by the Tukey-Kramer multiple comparison test. Data of two groups were compared by using the Student's $t$-test. For all the tests, $p<0.05$ was considered to be statistically significant. 


\section{Conclusions}

In the present study, we synthesized $\alpha$-D-mannose-modified $\alpha$-CD/PEG-based PRX, and examined its intracellular uptake in macrophage-like RAW264.7 cells. Intracellular Man-PRX uptake was observed in MMR-positive RAW264.7 cells but was negligible in the MMR-negative NIH/3T3 cells. In addition, the intracellular Man-PRX uptake in RAW264.7 cells was significantly decreased in the presence of free $\alpha$-D-mannose and anti-MMR antibody. These results suggest that Man-PRX was internalized in RAW264.7 cells specifically through MMR recognition. Moreover, our results showed that the polarization of RAW264.7 cells affected the internalization efficiency of Man-PRX. In addition, our results showed that Man-PRX was preferentially taken up by M2 macrophages that showed a high MMR expression level. According to these results, the modification of PRX using $\alpha$-D-mannose is an effective method for selective targeting of macrophages. Man-PRX contributes to the treatment and diagnosis of various diseases, including metabolic disorders.

Author Contributions: A.T., M.M., H.M., and N.Y. conceived and designed the experiments. K.S., A.T., and M.T. performed the experiments. K.S., A.T., and M.T. analyzed the data and K.S., A.T., and N.Y. wrote the paper.

Funding: This research was funded by the following grants: Grant-in-Aid for Young Scientists (A) from Japan Society for the Promotion of Science (JSPS) (JSPS KAKENHI Grant Number JP16H05910 to A.T.), Challenging Research (Exploratory) from JSPS (JSPS KAKENHI Grant Number JP18K19904 to A.T.), Noguchi Institute (to A.T.), Takahashi Industrial and Economic Research Foundation (to A.T.), and Cooperative project among medicine, dentistry, and engineering for medical innovation "Construction of creative scientific research of the viable material via integration of biology and engineering" from the Ministry of Education, Culture, Sports, Science, and Technology (MEXT).

Conflicts of Interest: The authors declare no conflict of interest.

\begin{tabular}{ll} 
Abbreviations \\
PRX & Polyrotaxane \\
CD & Cyclodextrin \\
MMR & Macrophage mannose receptor \\
Man-PRX & $\alpha$-D-Mannose-modified polyrotaxane \\
HEE-PRX & 2-(2-Hydroxyethoxy)ethyl carbamate-modified polyrotaxane \\
PEG & Poly(ethylene glycol) \\
CDI & 1,1'-Carbonyldiimidazole \\
DMSO & Dimethyl sulfoxide \\
Man-NH & 2-Aminoethyl $\alpha$-D-mannopyranoside \\
DBU & 1,8-Diazabicyclo[5.4.0]undec-7-ene \\
SEC & Size exclusion chromatography \\
FT-IR & Fourier transform infrared \\
NMR & Nuclear magnetic resonance \\
SPR & Surface plasmon resonance \\
APC & Allophycocyanin \\
CLSM & Confocal laser scanning microscopy \\
LPS & Lipopolysaccharide \\
IL & Interleukin \\
IFN- $\gamma$ & Interferon $\gamma$ \\
TNF- $\alpha$ & Tumor necrosis factor $\alpha$ \\
Arg-1 & Arginase-1 \\
MWCO & Molecular weight cut-off \\
HEPES & 2-[4-(2-Hydroxyethyl)piperazin-1-yl]ethanesulfonic acid \\
DMEM & Dulbecco's modified Eagle's medium. \\
& \\
\hline
\end{tabular}




\section{References}

1. Harada, A.; Li, J.; Kamachi, M. The molecular necklace: A rotaxane containing many threaded $\alpha$-cyclodextrins. Nature 1992, 356, 325-327. [CrossRef]

2. Wenz, G.; Han, B.; Müller, A. Cyclodextrin rotaxanes and polyrotaxanes. Chem. Rev. 2006, 106, $782-817$. [CrossRef] [PubMed]

3. Araki, J.; Ito, K. Recent advances in the preparation of cyclodextrin-based polyrotaxanes and their applications to soft materials. Soft Matter 2007, 3, 1456-1473. [CrossRef]

4. Tamura, A.; Yui, N. Threaded macromolecules as a versatile framework for biomaterials. Chem. Commun. 2014, 50, 13433-13446. [CrossRef] [PubMed]

5. Tamura, A.; Arisaka, Y.; Yui, N. Emergence of intelligent functions with supramolecular polymers and their biomaterials applications. Kobunshi Ronbunshu 2017, 74, 239-249. [CrossRef]

6. Tamura, A.; Yui, N. Lysosomal-specific cholesterol reduction by biocleavable polyrotaxanes for ameliorating Niemann-Pick type C disease. Sci. Rep. 2014, 4, 4356. [CrossRef] [PubMed]

7. Tamura, A.; Yui, N. $\beta$-Cyclodextrin-threaded biocleavable polyrotaxanes ameliorate impaired autophagic flux in Niemann-Pick type C disease. J. Biol. Chem. 2015, 290, 9441-9454. [CrossRef] [PubMed]

8. Tamura, A.; Yui, N. Polyrotaxane-based systemic delivery of $\beta$-cyclodextrins for potentiating therapeutic efficacy in a mouse model of Niemann-Pick type C disease. J. Control. Release 2018, 269, 148-158. [CrossRef]

9. Tamura, A.; Ohashi, M.; Nishida, K.; Yui, N. Acid-induced intracellular dissociation of $\beta$-cyclodextrin-threaded polyrotaxanes directed toward attenuating phototoxicity of bisretinoids through promoting excretion. Mol. Pharmaceut. 2017, 14, 4714-4724. [CrossRef]

10. Nishida, K.; Tamura, A.; Yui, N. ER stress-mediated autophagic cell death induction through methylated $\beta$-cyclodextrins-threaded acid-labile polyrotaxanes. J. Control. Release 2018, 275, 20-31. [CrossRef]

11. Tamura, A.; Yui, N. Rational design of stimuli-cleavable polyrotaxanes for therapeutic applications. Polym. J. 2017, 49, 527-534. [CrossRef]

12. Zimmer, S.; Grebe, A.; Bakke, S.S.; Bode, N.; Halvorsen, B.; Ulas, T.; Skjelland, M.; De Nardo, D.; Labzin, L.I.; Kerksiek, A.; et al. Cyclodextrin promotes atherosclerosis regression via macrophage reprogramming. Sci. Transl. Med. 2016, 8, 333ra50. [CrossRef] [PubMed]

13. Murray, P.J.; Wynn, T.A. Protective and pathogenic functions of macrophage subsets. Nat. Rev. Immunol. 2011, 11, 723-737. [CrossRef]

14. Wynn, T.A.; Chawla, A.; Pollard, J.W. Macrophage biology in development, homeostasis and disease. Nature 2013, 496, 445-455. [CrossRef] [PubMed]

15. Moore, K.J.; Sheedy, F.J.; Fisher, E.A. Macrophages in atherosclerosis: A dynamic balance. Nat. Rev. Immunol. 2013, 13, 709-721. [CrossRef] [PubMed]

16. Taylor, P.R.; Gordon, S.; Martinez-Pomares, L. The mannose receptor: Linking homeostasis and immunity through sugar recognition. Trends Immunol. 2005, 26, 104-110. [CrossRef] [PubMed]

17. Martinez-Pomares, L. The mannose receptor. J. Leukocyte Biol. 2012, 92, 1177-1186. [CrossRef] [PubMed]

18. Stahl, P.; Schlesinger, P.H.; Sigardson, E.; Rodman, J.S.; Lee, Y.C. Receptor-mediated pinocytosis of mannose glycoconjugates by macrophages: Characterization and evidence for receptor recycling. Cell 1980, 19, 207-215. [CrossRef]

19. Irache, J.M.; Salman, H.H.; Gamazo, C.; Espuelas, S. Mannose-targeted systems for the delivery of therapeutics. Expert Opin. Drug Deliv. 2008, 5, 703-724. [CrossRef]

20. Vedove, E.D.; Costabile, G.; Merkel, O.M. Mannose and mannose-6-phosphate receptor-targeted drug delivery systems and their application in cancer therapy. Adv. Healthc. Mater. 2018, 7, 1701398. [CrossRef]

21. Fujita, T.; Nishikawa, M.; Tamaki, C.; Takakura, Y.; Hashida, M.; Sezaki, H. Targeted delivery of human recombinant superoxide dismutase by chemical modification with mono- and polysaccharide derivatives. J. Pharmacol. Exp. Ther. 1992, 263, 971-978. [PubMed]

22. Kawakami, S.; Sato, A.; Nishikawa, M.; Yamashita, F.; Hashida, M. Mannose receptor-mediated gene transfer into macrophages using novel mannosylated cationic liposomes. Gene Ther. 2000, 7, 292-299. [CrossRef] [PubMed]

23. Tahara, N.; Mukherjee, J.; de Haas, H.J.; Petrov, A.D.; Tawakol, A.; Haider, N.; Tahara, A.; Constantinescu, C.C.; Zhou, J.; Boersma, H.H.; et al. 2-deoxy-2-[18F]fluoro-D-mannose positron emission tomography imaging in atherosclerosis. Nat. Med. 2014, 20, 215-219. [CrossRef] [PubMed] 
24. Azad, A.K.; Rajaram, M.V.S.; Schlesinger, L.S. Exploitation of the macrophage mannose receptor (CD206) in infectious disease diagnostics and therapeutics. J. Cytol. Mol. Biol. 2014, 1, 1000003. [CrossRef] [PubMed]

25. Wada, H.; Hyun, H.; Bao, K.; Lee, J.H.; El Fakhri, G.; Choi, Y.; Choi, H.S. Multivalent mannose-decorated NIR nanoprobes for targeting pan lymph nodes. Chem. Eng. J. 2018, 340, 51-57. [CrossRef] [PubMed]

26. Ehashi, T.; Hyun, H.; Yui, N. Anti-inflammatory response of mannose-conjugated polyrotaxane endocytosed into macrophage. Macromol. Res. 2011, 19, 495-500. [CrossRef]

27. Hyun, H.; Yui, N. Mono-, di-, or triazidated cyclodextrin-based polyrotaxanes for facile and efficient functionalization via click chemistry. Macromol. Rapid Commun. 2011, 32, 326-331. [CrossRef]

28. Hyun, H.; Yui, N. Ligand accessibility to receptor binding sites enhanced by movable polyrotaxanes. Macromol. Biosci. 2011, 11, 765-771. [CrossRef]

29. Hu, X.; Gao, J.; Luo, Y.; Wei, T.; Dong, Y.; Chen, G.; Chen, H. One-pot multicomponent synthesis of glycopolymers through a combination of host-guest interaction, thiol-ene, and copper-catalyzed click reaction in water. Macromol. Rapid Commun. 2017, 38, 1700434. [CrossRef]

30. Tamura, A.; Nishida, K.; Yui, N. Lysosomal pH-inducible supramolecular dissociation of polyrotaxanes possessing acid-labile $N$-triphenylmethyl end groups and their therapeutic potential for Niemann-Pick type C disease. Sci. Technol. Adv. Mater. 2016, 17, 361-374. [CrossRef]

31. Tamura, A.; Ohashi, M.; Yui, N. Oligo(ethylene glycol)-modified $\beta$-cyclodextrin-based polyrotaxanes for simultaneously modulating solubility and cellular internalization efficiency. J. Biomater. Sci. Polym. Edit. 2017, 28, 1124-1139. [CrossRef] [PubMed]

32. Lu, F.; Song, B.; He, P.; Wang, Z.; Wang, J. Electrochemical impedance spectroscopy (EIS) study on the degradation of acrylic polyurethane coatings. RSC Adv. 2017, 7, 13742-13748. [CrossRef]

33. Harada, A.; Li, J.; Kamachi, M. Formation of inclusion complexes of monodisperse oligo(ethylene glycol)s with $\alpha$-cyclodextrin. Macromolecules 1994, 27, 4538-4543. [CrossRef]

34. Ruan, G.X.; Chen, Y.Z.; Yao, X.L.; Du, A.; Tang, G.P.; Shen, Y.Q.; Tabata, Y.; Gao, J.Q. Macrophage mannose receptor-specific gene delivery vehicle for macrophage engineering. Acta Biomater. 2014, 10, 1847-1855. [CrossRef]

35. Martinez-Pomares, L.; Reid, D.M.; Brown, G.D.; Taylor, P.R.; Stillion, R.J.; Linehan, S.A.; Zamze, S.; Gordon, S.; Wong, S.Y. Analysis of mannose receptor regulation by IL-4, IL-10, and proteolytic processing using novel monoclonal antibodies. J. Leukoc. Biol. 2003, 73, 604-613. [CrossRef]

36. Ulrich, G.; Ziessel, R.; Harriman, A. The chemistry of fluorescent bodipy dyes: Versatility unsurpassed. Angew. Chem. Int. Edit. 2008, 47, 1184-1201. [CrossRef] [PubMed]

37. Mantovani, A.; Sozzani, S.; Locati, M.; Allavena, P.; Sica, A. Macrophage polarization: Tumor-associated macrophages as a paradigm for polarized M2 mononuclear phagocytes. Trends Immunol. 2002, 23, 549-555. [CrossRef]

38. Biswas, S.K.; Mantovani, A. Macrophage plasticity and interaction with lymphocyte subsets: Cancer as a paradigm. Nat. Immunol. 2010, 11, 889-896. [CrossRef] [PubMed]

39. Jablonski, K.A.; Amici, S.A.; Webb, L.M.; de Dios Ruiz-Rosado, J.; Popovich, P.G.; Partida-Sanchez, S.; Guerau-de-Arellano, M. Novel markers to delineate murine M1 and M2 macrophages. PLoS ONE 2015, 10, e0145342. [CrossRef]

40. Van den Bossche, J.; Baardman, J.; Otto, N.A.; van der Velden, S.; Neele, A.E.; van den Berg, S.M.; Luque-Martin, R.; Chen, H.J.; Boshuizen, M.C.; Ahmed, M.; et al. Mitochondrial dysfunction prevents repolarization of inflammatory macrophages. Cell Rep. 2016, 17, 684-696. [CrossRef]

41. Monguió-Tortajada, M.; Roura, S.; Gálvez-Montón, C.; Pujal, J.M.; Aran, G.; Sanjurjo, L.; Franquesa, M.; Sarrias, M.; Bayes-Genis, A.; Borràs, F.E. Nanosized UCMSC-derived extracellular vesicles but not conditioned medium exclusively inhibit the inflammatory response of stimulated $\mathrm{T}$ cells: Implications for nanomedicine. Theranostics 2017, 7, 270-284. [CrossRef] [PubMed]

42. Araki, J.; Zhao, C.; Ito, K. Efficient production of polyrotaxanes from $\alpha$-cyclodextrin and poly (ethylene glycol). Macromolecules 2005, 38, 7524-7527. [CrossRef]

43. Sardzík, R.; Noble, G.T.; Weissenborn, M.J.; Martin, A.; Webb, S.J.; Flitsch, S.L. Preparation of aminoethyl glycosides for glycoconjugation. Beilstein J. Org. Chem. 2010, 6, 699-703. [CrossRef] [PubMed]

44. Chung, E.S.; Lee, G.; Lee, C.; Ye, M.; Chung, H.S.; Kim, H.; Bae, S.J.; Hwang, D.S.; Bae, H. Bee venom phospholipase A2, a novel Foxp $3^{+}$regulatory $\mathrm{T}$ cell inducer, protects dopaminergic neurons by modulating neuroinflammatory responses in a mouse model of Parkinson's disease. J. Immunol. 2015, 195, 4853-4860. [CrossRef] [PubMed] 
45. Frison, N.; Taylor, M.E.; Soilleux, E.; Bousser, M.T.; Mayer, R.; Monsigny, M.; Drickamer, K.; Roche, A.C. Oligolysine-based oligosaccharide clusters: Selective recognition and endocytosis by the mannose receptor and dendritic cell-specific intercellular adhesion molecule 3 (ICAM-3)-grabbing nonintegrin. J. Biol. Chem. 2003, 278, 23922-23929. [CrossRef] [PubMed]

46. Manders, E.M.M.; Verbeek, F.J.; Aten, J.A. Measurement of co-localization of objects in dual-colour confocal images. J. Microsc. 1993, 169, 375-382. [CrossRef]

Sample Availability: Samples of the compounds are available from the authors.

(C) 2019 by the authors. Licensee MDPI, Basel, Switzerland. This article is an open access article distributed under the terms and conditions of the Creative Commons Attribution (CC BY) license (http:/ / creativecommons.org/licenses/by/4.0/). 